

\section{'Don't you feel bad watching the Olympics, watching us?' A qualitative analysis of London 2012 Olympics influence on family sports participation and physical activity.}

\section{Abstract}

This paper examines the use of video diaries (VDs) and their value as supplementary methods in qualitative research examining the influence of the London 2012 Olympics, from the perspectives of five families in the East Midlands of England.

The aims of the project were to assess their reaction to the Games, the influence it had on family attitudes, opinions and perceptions towards sports participation and physical activity (PA). We present qualitative interview data from pre and post Games interviews and VD data to gather micro realities of the influence of the Games. We draw on Erving Goffman's (1959) dramaturgical perspective to explore the perspectives of families regarding the impact of the Olympics on their everyday lives. It has yielded the following themes: access, motivation, inspiration, apathy and reflection on methodological use of VDs .

The benefits and challenges of VD use alongside Goffman's framework are discussed in the context of assessing the impact of the Games on these families. Our evidence suggests that these methods are an invaluable tool for accessing the families' immediate responses to megaevents during the period in which they are hosted. However, the feasibility and complexities of utilising VDs are presented, as we consider whether these methods assist researchers to examine the uptake of sports participation, or simply encourage the researchers to become voyeurs watching the participants, watch the Olympics. The implications for using these methods as part of qualitative methods for analysis of the sports participation legacy and the impact of future mega events are discussed.

Keywords: London 2012 Olympics; Qualitative methods; video diaries; Erving Goffman; families and East Midlands

\section{Introduction}

The London 2012 Olympic Games assured to inspire a generation and, for the first time in Olympic bid history, the government promised to invest in delivering a permanent increase in the number of people playing sport as a result of the Games (DCMS, 2009). The Government department for sport's policy document Creating a Sporting Habit for Life (2012) established a vision of a positive future 2012 legacy and an upwards trajectory of sports participation (Mackintosh et al., 2014). However, the success of this legacy has been criticised because sports participation $^{1}$ figures of regular involvement ${ }^{2}$, amongst young people (16 to 25 -yearolds) and adults (over 26 years) have dropped since the Games (Sport England, Active People

\footnotetext{
${ }^{1}$ Participation in 30 minutes of moderate intensity sport.

${ }^{2} 1$ session a week (at least 4 sessions of at least moderate intensity for at least 30 minutes in the previous 28 days). (Sport England APS, 2013-14).
} 
Survey, 2013-14). Despite this, the Coalition government has continued to focus on broadcasting the overall increased levels of adult sports participation since the bid was won in 2005 (Gibson 2013).

Qualitative research examining the influence of Olympics to the sports participation legacy is partial. Difficulties arise when researching mega-events because access to participants for an extended period prior to, during, and following the event is often limited by family and work commitments (Carter and Lorenc 2013). Although visual culture is embedded in the representation and consumption of the Olympics, there are no studies, as yet, that have utilised video methods to examine the 2012 sports participation legacy. Herein lies part of the rationale for this research project. Visual research methods, as supplementary methods in qualitative research, can provide a detailed exploration of the impact and experiences of the London 2012 Olympics Games from the perspectives of families in the East Midlands region of England. The specific research aims of the project were:

- To examine the use of video diaries and their value as supplementary methods in qualitative research examining the influence of the London 2012 Olympics, from the perspectives of five families in the East Midlands of England.

- To explore the influence of London 2012 Olympics on family attitudes, opinions and perceptions towards sports participation and physical activity

The 2012 London Olympics was viewed by a record number of people across the globe and represented a vast development to online and mobile environments (Tang \&Cooper 2013). The various forms of media coverage 'put the Olympics in the reach of 4.8 billion people' (Billings \&Hardin 2013, p.847). The mediated format of the Games was categorised, metaphorically by Lord Seb Coe as a 'well-stocked shop window [in which]...the performance of the stars in the Games...gets people involved' (The Telegraph 2011). The London Organising Committee (LOC) perceived the representation of successful heroes and heroines as the tool to increase participation. The LOC envisaged that this mass participation effect would be stimulated by the extensive multi-platform media coverage of the 2012 Games. However, critics argue that this was one of the most ambitious Olympics legacies, as previous Games had not employed strategies towards raising sport participation or PA (Carmichael et al. 2013, Weed et al. 2009). Furthermore, 'most of the evidence suggests that major sporting events have no inevitable positive impact on...sporting participation' (Coalter 2004, p. 11). Whilst initiatives such as People, Places and Play, seek to get two million members of the population participating in sport (Sport England 2012), there is a heavy reliance on the power of media to influence people's lives. But, if they were watching, did they participate in response to their media consumption, or did many spend more time watching and less time participating?

Research examining the influence, or the potential influence, of the London 2012 Olympics to sports participation begun to emerge in the last two years. Whilst quantitative analyses provide an invaluable insight into post-Olympic participation trends (Carmichael et al. 2013), qualitative interviewing can make it possible to ask more exploratory 'questions relating to 
respondents' perceptions of elite sport', their thoughts and attitudes relating to success in specific sports and sports participation (Carmichael et al. 2013, p.37). Furthermore, they allow for exploration of the spectator's 'opinions ... feelings and attitudes... and reveal... more about the meanings they attach to their experiences' (Smith and Sparkes 2013, p.84). Application of these methods allows us to recognise 'that different groups will experience the Games, and be impacted by them, in different ways' (Silk 2011, p.735). This project has aimed to access the raw thoughts and meanings attached to the games and some of the most localised implications for families, individuals and potential sport communities.

Qualitative research examining the London 2012 Olympics and its impact on sports participation in the UK is minimal (Mackintosh et al, 2014). The studies that exist, have analysed the build-up to the Games and the plans to deliver the participation legacy. For example, Carter and Lorenc (2013) have examined the impact of the demonstration and festival effect. Despite this evidence, there is a gap in the qualitative research evidence that examines specifically the spectators' response to their consumption of the 2012 Olympics, and its impact to attitudes, opinions and perceptions on sports participation behaviour and PA (Frawley 2013).

\section{Visual research methods and the London 2012 Olympics}

It has been proposed that 'the exploration of the...social world...requires methodological approaches that encompass these developments with methods that are both mobile and visual' (Murray 2009, p. 470), and the use of visual research methods allows for this mobility. However, the studies that have utilised these methods to examine the impact of the London 2012 Olympics are still in their infancy. Despite this, researchers argue for their value in sport and exercise sciences (Phoenix \&Smith 2011). Visual data, gathered through these methods, act as forms of data that can access meanings and emotions that can be inaccessible to the researcher through standard qualitative methods (Cherrinton \&Watson 2010). Visual images (moving or still) can encourage participants to discuss the multiple meanings they attach to their subjective experiences and describe the structures, spaces and processes that shape these meanings (Bates 2015). Researchers examining the London 2012 Games support the value of these methods and have used them in different ways (Kennelly \& Watts 2012; Würfel 2012).

The use of the visual as part of a qualitative study can empower the participants in the research process (Pink 2013), particularly when they feel disempowered in their access to the Games (Kennelly \&Watts 2012). Power relations between the researcher and the researched can be renegotiated when participants represent their lives through photography or video (Holliday 2004, Pink 2013). Empowerment evolves through their involvement of sharing their experiences and thoughts and attitudes. As many of the Olympic spectators experienced the Games from distanced position, this approach also offers the participant greater editorial control over the material revealed (Holliday 2004) and allows them to participant in this megaevent in a different way; that is visually.

\section{Erving Goffman: Dramaturgy}


In this article we draw upon the Erving Goffman's (1959) dramaturgical perspective as an analytical frame to help further understand the impact Olympic role models have to spectators' attitudes, opinions and perceptions of sports behaviour and PA. Goffman's discussion of self in The Presentation of the Self in Everyday Life gives us a way of understanding the participants reaction to the Games. We suggest that video diaries allow us to examine the less public spaces of family life and aspects of the self that are concealed behind public performances. We therefore, consider what impact this method may have on understanding family member's perspectives of the impact of the Olympics to their everyday lives. Goffman is used as a supporting theoretical frame for exploring our substantive aim looking at participation (but not exclusively). Equally, it can support critical understanding of everyday life explored through a video diary. It is not that we aim to exhaustively explain all aspects of video diaries by highlighting the use of Goffman.

Using the analogy of the theatre, Goffman argues that individuals are present on a public theatrical stage and bodily performances that are required for this dramaturgical world are developed through shared interaction with others and cultural expectations of identities. He allows for an understanding of the behaviour which illustrates the way in which performance can be managed through 'front' and 'back' regions. Within his framework, the front stage is conceptualised as the location/s in which one presents a publicly accepted self; while the backstage allows for aspects of self which is separated, hidden and controlled in interaction. Control of boundaries and knowledge - specifically the boundary between the front and back stages, and knowledge about appropriate conduct in each are central to Goffman's understanding of identity performance (Darko 2012).

Front stages 'refer to the place[s] where performances are given' (Goffman 1959, p. 107). In our research they include public spaces in the family member's lives such as schools, parks, streets, and the Olympic venues. In contrast to the front stage, Goffman (1959, p. 112) agues there are also back stages in which individuals 'can relax; ... drop his front' and express behaviour that differs to their front region performance. Here the 'impression of the performance is knowingly contradicted' (Goffman 1959, p. 114). These spaces include the family homes; bedrooms and living rooms. The 'roles' and 'manners' adopted by family in these regions are less bounded by the exigencies of the public front (Goffman 1959). Exploration of these back stage performances through video dairies allows us to focus on the micro-world of the family member's everyday lives as the core social context. The home space as of this project included the living room, children's bedrooms, the kitchen and other internal domestic spaces of their lives.

\section{Methodology}

\section{Overview of methods}

We sought to understand people in their natural environments and the influence of the social meanings within their everyday lives. We recognise the individual's actions, behaviours and interactions as being central to understanding (Mason 2002) the families' responses to the Games. We therefore focus on how the social world is interpreted, and experienced by the 
family members. The interpretvist approach underpins our design and analysis as we seek to examine the meanings individuals give to the Games, and their responsive actions (Smith \&Sparkes 2013). In particular it is also worth recognising the seminal work of Morley (1986) where families were interviewed in depth to gain access to how television played a role within their leisure activities. In particular, there is a parallel with our own project because "the aim was to gain insight into the terms within which our respondents defined their viewing activities” (Morley 1986, p. 51). This position of television related to making choices is also helpful in highlighting the complex interplay between the family 'at home', viewing consumption and sporting behaviour (or lack of).

Informed by these positions we utilised in-depth interviews and participant video diaries to address the exploratory research questions. The video diary in this project was used to access and capture the raw thoughts of respondents through the period of data capture. It was not, in this paper, used as a tool in visual analysis of behaviour, clothing and so forth. In this sense the video is employed in the manner that others have utilised blogs and digital technologies that are becoming increasingly well established to gather raw thoughts of respondents (Murthy, 2008). We sought to discover whether the families changed their values, attitudes and behaviours around PA and sports participation due to the presence of 2012 Olympic Games.

Five families were sampled from across four different local authorities in the East Midlands of England. An overview of the demographic breakdown of the families that undertook the project is in Table 1 below. Families were recruited through local media recruitment. Research ethics was undertaken through the university ethics committee and included all families and children engaged in the process of giving informed consent, the right to withdraw, and the right to anonymity in the dissemination of the video diary entries.

Table 1- Demographic breakdown of the families

\begin{tabular}{|l|l|}
\hline Family 1 & $\begin{array}{l}\text { Father }-37 \text { yrs, professional white collar manager. } \\
\text { Mother }-35 \text { nutritionist and personal trainer. } \\
\text { Son } 1-5 \text { yrs, Son } 2-3 \text { yrs, Daughter } 1-2 \text { yrs. } \\
\text { Home owners, suburban new housing estate, Nottingham City Council } \\
\text { Local Authority (LA), Nottinghamshire. }\end{array}$ \\
\hline Family 2 & $\begin{array}{l}\text { Mother } 38 \text { yrs, architect project manager. } \\
\text { Father } 39 \text { yrs, gardener. } \\
\text { Daughter } 1-14 \text { yrs, Daughter } 2-11 \text { yrs. } \\
\text { Rented property, urban-rural fringe council estate, Gedling LA, } \\
\text { Nottinghamshire. }\end{array}$ \\
\hline Family 3 & $\begin{array}{l}\text { Single Mother aged } 49 \text { yrs, unemployed. } \\
\text { Son } 1-17 \text { yrs, Daughter } 1-13 \text { yrs, Son } 2-9 \text { yrs, Daughter } 2-6 \text { yrs. } \\
\text { Inner city, rented property, Leicester City LA. }\end{array}$ \\
\hline
\end{tabular}




\begin{tabular}{|l|l|}
\hline Family 4 & $\begin{array}{l}\text { Family declined to stay involved in project after partial initial } \\
\text { involvement. Reason: time and family pressures. }\end{array}$ \\
\hline Family 5 & $\begin{array}{l}\text { Mother } 43 \text { blue collar office worker } \\
\text { Father } 45 \text { mature student } \\
\text { Son } 1-12 \text { yrs, Son } 2-10 \text { yrs. } \\
\text { Home owners, suburban area, Broxtowe LA, Nottinghamshire. }\end{array}$ \\
\hline
\end{tabular}

For the first stage of the data collection family interviews with focus group discussions were conducted one week prior to the Games. Data collection for these interviews entailed a semistructured format and open ended questions encompassing a thematic topic guide to establish existing participation, attitudes and involvement in sport and PA, aspirations and views on the Games, and expected impact on family and individual behaviour change (Smith \& Caddick 2012). Stage two of the data collection drew upon digital video cameras located in the families' homes for the duration of the research. Video diaries were utilised to gain insight into the family's perspectives of the Games. By utilising visual phenomena that are present in their everyday lives (Pink 2013), we envisaged that this method would create opportunities for encouraging families and the young members to participate in the research (Cherrington \& Watson 2010). As discussed above, we provided an open format guide, aligned to the central themes of the research and asked them to comment on their level of consumption during the Games (Braun \& Clarke 2013), their interpretations of the Games, the athletes and events, and whether their consumption has impacted on their level of motivation or inspiration to participate in sports and/or PA.

The final stage of the data collection was completed during the post-Olympic period one month after the event. Initial data analysis of stage one interviews were fed into this, to probe certain topics that had been uncovered in the initial phase of interviews. Furthermore, the interview topic guide was amended to incorporate changes in views having experienced the event and to gain rich insights into the multiple ways the Games were consumed by the various families and individuals

Once all the data were collected and transcribed they were coded thematically across the various transcripts of interview and video-generated data (Braun \& Clarke, 2013). This coding was employed after the first (pre-Olympics) interviews to build initial broad categories of themes within the data. More detailed groupings of individual codes (Silverman 2006) allowed for the emergence of specific focuses across the three phases of data that had been developed. This coding process was also undertaken across individuals within the multiple researcher team to allow for further refinement of the analysis (Saldaña 2013).

\section{Video Diaries}

There has been rise in the use of video diaries in sports research (Cherrington and Watson 2010, Jones et al. 2014), yet they have not been utilised to examine the impact of the 2012 Olympics on sports participation and PA. They are a visual participatory tool that can further 
our understanding of people's interaction with the Games and the impact on their everyday lives.

Diaries as a form of respondent generated data (Gibson 2005, Smith and Sparkes 2013), provide the researcher with instantaneous and time-bound reflections from the perspectives of Olympic spectators. These immediate responses cannot always be achieved by using traditional qualitative interviewing (Rose 2007). They differ because 'the entries are made at the time or close ...to the time when events ...occurred so that the record is not distorted by problems of recall' (Alaszewski 2006 p. 45). As diary entries are often located within the social context of the participants' everyday lives, we can also access understanding about how the presence of the Olympics interacts with their daily activities. Potentially these methods create 'greater closeness between the experience [of the Games] and the [research] record of experience' (Bijoux and Myers 2006, p.49).

This participatory method can also decrease the gap between the researchers' perceptions and those of individuals 'by giving participants control of the camera and the process of making their daily experiences visible' (Jewitt 2012, p.3). As the demonstration effect suggests elite sport inspires spectators to participate in their social context (Weed et al. 2009), 'diaries offer the opportunity for the recording of events and emotions in the participants' social context' (Hawkes et al. 2009 p. 213). This gives us a close up insight to the micro reality of this often assumed key area of policy rhetoric from the perspective of families geographically distant from the Games.

There are different types of video diaries; closed and open format (Braun and Clarke 2013). The former is generally structured with a set of questions. The latter seeks to collect information from participants that is 'descriptive or reflective in nature' (Hawkes et al. 2009, p.213). Open diaries can be critiqued for being an intermittent process. The temporal nature of recording data means that diary keeping can change with each entry (Hawkes et al. 2009). However, 'video data ..., like all data, is partial, it includes and excludes elements' (Jewitt 2012, p. 5). Furthermore, changes that occur with each diary entry 'reflects more accurately the diverse range of thoughts and feelings that make up daily life' (Hawkes et al. 2009 p.213). This approach recognises that our attitudes to mega-events and the athletes are not necessarily homogenous, static and persistent over a set period of time. In accordance with this position, we value the transitory process of diary making itself.

\section{Challenges and Constraints of Video Dairies}

Video diaries entries can be shortened by the participant, as they choose when to turn on and off the camera, or delete sections that they feel are irrelevant or are unsatisfied with (Braun and Clarke 2013). Arguably, it is at this point we can miss important features for analysis (Hawkes et al. 2009). However, 'participant generated video accounts can...be analysed not only for content but also for how participants engage in identity construction’ (Gibson 2005 p. 5). Perhaps the Olympics inspires spectators to perceive and, thus, represent themselves in the best 
possible light: as 'a sports mad nation', participating more frequently, and 'get[ting] fitter' (Coalter 2004, p. 3). Whilst quantitative surveys can provide us with a one-off response to the Olympics and its impact on PA, the process of video diary making allows the audience to independently record their responses at different moments in their daily lives and discuss the possible impact on their identity construction.

The challenges of video diaries can also lie in their presence in people's lives. Whilst they provide greater access to the private spaces (or back stages) of participant's lives, this can prevent participants from becoming involved in the research (Goffman, 1959, Pink, 2013). Participants may initially agree to the presence of the cameras, but may find its presence intrusive. This can ultimately lead some to withdraw or alter the style of their diary keeping. To address this, additional ethical measures can be taken, and were taken in this research, to allow participants to understand the level of commitment and the right to withdraw. However, this requires reflexive engagement on the part of the researcher concerning that ethical process itself and the type of participant involvement (Pink 2013).

\section{Findings}

\section{Access to the Games}

Our data revealed frustration amongst each of the families about the inaccessibility to the Games. For these families economical positioning played a central role in their access (Green 2012). This was discussed by all of the family members in the interviews. In his seminal study including unemployed television family members, Morley (1986) recognised that whilst they had limited realistic access to participation, the television opened the opportunity to being involved. Physical inaccessibility to events was less pertinent than gaining direct viewing of a route to improving their own sporting skills, behaviour and professionalism. However, the prevalence of the issue in this study was made more apparent to us through the video diary method, as family members provided repeated comments about their inaccessibility in different diary entries over the duration of the two weeks. Coupled with the comments made in the pre and post-Olympic interviews we accessed deeper understanding of the impact this has on the family's interaction with the Games. As the respondents felt disempowered in their access to the Games, the video 'demarginalises the voice of respondents' (Murthy, 2008, p. 837) and empowers them in the research process. In the following diary entries, Family Member 2, (the father) in Family 5, expresses his frustration at the inaccessibility of the Games. For this father access to the elite sport is denied to those who cannot afford it:

Video Diary Entry Four:

Lots of empty seats...! The whole ticket system...is totally...wrong, and it's just rewarding the rich! People who can afford to pay silly amounts of money for tickets get to go to the Olympics. There are lots ... of people who would love to go but they just can't afford it! Lots of people who love the different sports and they would love to go and see these people but they can't, and yet you see all these empty seats! It's wrong, the system is wrong and it needs changing, especially for the next Olympics. 
Video Diary Entry Fifteen

I still wish I could go, it would be nice to go but the way the tickets are and everything, it just wasn't possible for us I'm afraid!

For all of these families improved access to the Games through a more affordable ticketing system would have encouraged further attendance and future participation. One family member (FM1) also suggested that the LOC should have hosted more events in local landscapes and at local facilities to develop the sports participation legacy. This inevitably would have reduced travel costs for local families and drawn attention to the potential for participation in localised regions:

They've ...put a sandbox in the middle of London which apparently classifies as a beach volleyball... that's it really stupid. There are plenty of beaches so they should actually use one!' (Mother, FM 1, video diary entry).

\section{Motivation, inspiration and role models}

The LOC envisaged that the representation of role models, through the process of the demonstration effect, would have a trickle-down effect on the motivation to take part in sport and PA (Coalter 2004, Weed 2009). Our data supported this approach, as some family members revealed that were enthused by the representation of successful athletes. The interviews provided an insight into their perceptions of the athletes and the impact on the families' everyday lives, and yet the videos provided visual and verbal understandings of how some family members embodied athletic identities and utilised them in their identity construction.

We found that these respondents engaged in a confessional narrative through 'a narcissistic identification with an imagined viewer' (Holliday 2004 p. 53). This entailed self-indulgent discussions about their personal behaviour, rather than the family per se, and represented constructions of an imagined ideal self. Arguably the respondents are aware of cultural expectations of the sports body and health appropriate behaviour, and seek to present themselves in this best possible light to an imagined public audience (Goffman 1979). Whilst these narratives can be criticised by realists for failing to present an undistorted objective reality (Pink 2013), we argue in these instances we are given a greater insight to the meanings the subjects attach to their spectatorship and the role the athletes play in their identity construction. In the following diary entries, one adult family member explains how the Games has inspired her to participate new activities, participate more frequently and train harder in existing activities. She also confesses to altering aspects of her sports identity and sense of self in response to an athlete's eating behaviour. Whilst she dislikes concentrating on her nutritional intake, she admits to improving it to mimic particular athletes:

Diary entry thirteen.

FM1 (Family 1) I've been thinking about whether it is inspiring for me to do more exercise and I think that already I'm training lots more. Tomorrow... I will be training 
again so it probably is and then I'm thinking then again the athletes do it and show focus so... yeah it probably is making a difference.

Diary entry fifteen.

I watched Jessica Ennis and the long jump....and Mo Farrah! And tonight been out for a run, this morning...carried on with the biking. I've been inspired by Victoria Pendleton and I was hoping to watch her tonight... I did watch the cycling earlier. It's all going really well, it has made a difference, I'm really surprised by that, it has made me think about what I'm doing and how I can pick up the pace and concentrate on the nutrition which I don't at all.

Dairy entry sixteen

This is the article I read on health and fitness (shows the camera the magazine article) and these are the kind of things I'm reading all the time ...leading up to the Olympics and now they are really sinking in. This is by Hannah McClowd and she's a GB hockey forward and she says what they do is they... don't eat anything that doesn't grow, walk or swim so this is what I am going to ... do but I am really bad with food! So I'm going to have a go...this magazine is quite inspirational.

Similarly, others family member reveal that they were enthused by the representation of successful athletes. For example, the mother in Family 5 expresses a level of identification with an Olympic role of comparable age. However, she does not perceive this as having a trickledown effect on her motivation to take part in sport and PA

'I was quite chuffed that one of the female athletes was just coming up to her fortieth birthday! And I'm thinking oh my god she's an Olympian and she's just coming up to forty but... I felt like I have reached an age now where it wouldn't be inspirational for me personally'.

Whilst we family members identified with Olympic role models can, we also found that this is not attributed to single individuals with comparable identities. The video diary entries revealed that identification, motivation and inspiration crosses sports disciplines, race, sex and age categories. FM1 is female and yet identifies with both male and female athletes who participate in different sports and whose age and race varies to her own. Similarly, one of the young family members (FM 3 family 3) is a white male and presents signs of admiration for black Caribbean athletes Usain Bolt and Yohan Blake in his video diary entries. The fluidity of identity boundaries that exist in contemporary sport allows some spectators to perceive sporting heroes and heroines as epitomizing social ideals and as embodying values that can be transferred into their everyday lives and identity construction (Lines 2001). The video diary allows for further understanding of the level of identification and identity construction, as we are given visual displays, or bodily expressions of approbation by the child (Goffman 1959).

FM 3 (Family 3) I really like Usain bolt. Today...we were doing this (football) game, when I came to the end I just went like that (family member jumps in the air and demonstrates bolt pose). It was really good (repeats pose). Oh yeah Mo Farrah! He 
goes like this (Mo pose with eyes crossed) he goes like this because he just loved team GB...I saw Yohan Blake! (Pulls scary face and claw hand actions) I saw the mighty master, he came in like (Pulls up top and demonstrates the Usain Bolt pose).

Other young male family members also express visual admiration of Usain Bolt in their video diary entries. Following questioning from their mother, they too express their appreciation for Usain through their embodied imitation of his iconic poses. In accordance with the Olympic athlete, they seek to present themselves in the best possible light and will adhere to roles that are compatible with the cultural expectations of the celebrity sports identities and the concomitant masculinities at that point in time (Goffman 1959):

Family Five

FM 2: So then how much of the Olympics have you been watching over the last few days?

FM 4: Bolt!

FM 2: Ok, anything else?

(FM3 demonstrates Bolt pose in the background)

FM 2: oh sorry "family member three” what was that?

FM3: I did that! (FM 3 \&4 demonstrate Bolt Pose)

(FM3 shows off his bicep muscles and kisses them).

Goffman's (1959) dramaturgical analysis can be drawn on as an analytical tool for understanding this behaviour and the role-modelling effect believed to be inherent in the sports participation legacy. Usain Bolt and Yohan Blakes' behaviour can be conceptualised as role playing expressed through bodily gestures and movement as part of their 'personal front', located on the front stage region of the public Olympic stadium (Goffman 1959, Darko 2012). As discussed above, this region' is conceptualised as public space with a viewing audience. Here there is a cultural standard of behaviour that individuals adhere to. This behaviour is consciously aligned to the cultural expectations of masculine roles and performances within that sporting space. As part of their identity construction these male participants seek to reflect the cultural expectations of the male Olympic athlete and the idealised standard of masculinities.

Whilst all of these young men adopted the role and performances expressed by the Olympic athletes, only two of them admitted to being directly motivated by them to participate in sport. Consequently, Goffman's approach can be drawn on to understand the overtly conscious aspects of role modelling behaviour, but application in its entirety requires further theoretical development. We cannot assume that all members of society are concerned with the presentation of the self and adherence to specified roles, as is understood in Goffman's 
dramaturgical analysis and is inherent in role model approach (Coalter 2004, Horne \& Whannell, 2012). This challenges the notion that the role model effect would inspire an entire generation.

\section{Apathy}

Unfortunately, the impact of the role model effect was not apparent for the remainder of the young people in the research. There appeared to be apathy towards the games and the presumed sports participation legacy. The majority of young people consumed aspects of the games, but few were inspired or motivated to participate in response to their spectatorship . One parent (Family 5) explained:

FM1: I can't really say that the children are being dragged or pulled towards any of the big events or have actually said I really... want to try that because we've seen it on the Olympics.

For some young people the couch potato effect was induced by the extensive sports media coverage (Veal, 2003). For example, one young (female) family member (FM 3, Family 2) recognised the decline in her sports participation and PA as a result of watching the games, but was also reflective about the guilt of watching and the presumed sports participation legacy:

You don't want have to worry about doing sport and stuff [because] you can sit down all day and watch this, which is the opposite of Olympic spirit...you feel bad watching the Olympics, watch us instead.

Young people who chose not to watch the Games, recognised a decrease in their PA as a result of trying to avoid media consumption. FM 4 (Family 5) explains:

'It has actually made me less active because I don't want to watch it, so...I'm in my room'.

Whilst the couch potato effect recognises the declines in sports participation as a result of the media coverage. Perhaps we need an additional feature to this model that recognises the twofold effect, embedding avoidance of the Games. The role of other family members is significant because their media consumption of the Games at home can impact on the sports participation activities that the family could take part in collectively. As Morley (1986) has suggested when family members select programmes to view it serves to actually organise family interaction and in some cases decrease interaction. This specific interaction between viewing and participation requires further examination.

Whilst we found that the media portrayal and lack of access to the Games impacted on physical participation, there were additional factors preventing young people taking part in sports. One young family member revealed that public participation in PA is perceived negatively amongst her peers and thus limits their involvement. The private back space of the home offered some young people (notably females) the freedom to participate in video active games away from peers (Goffman 1959). Coincidently, the video diary situated in this space also allowed them to openly discuss their perceived apathy and peer pressures. The young participant explains: 
FM4: (Family 2) There's a lot of pressure on people our age they are just like 'why are you doing that?'... I would love to just be able to go for a jog like outside, but if I saw my friends I'd have the eternal mickey taken out of me and anyone will just think why is a 12 year old going jogging it's a bit weird! ...I don't like doing it on the WII Fit jogging on the spot, I'd love to be able to just go outside.

For some young family members the presence of the video camera and their involvement in presenting themselves to it, became a potential source of embarrassment amongst their peers. Consequently, some young people perceive an imagined viewer who can be central to their embarrassment among their peers (Holliday 2004). For example, FM1 (family 1) and FM1 (family 5) explain:

FM 1 (Family 1): 'I did ask [family members four and five] to say something but when it came to it they were too embarrassed'.

FM 1 (Family 5): 'Family member three is being a little bit shy so they don’t want to be on the final video'.

Implications for further research and examination of the long-term sports participation legacy are to use mobile phone diaries to explore young people's response to the Olympics in their everyday lives. As some of the young people in our research were less responsive to the use of video cameras, mobile phone diaries are potentially more feasible for young people. The mobility of the smart phone allows young people to take it with them to the various front and back regions of their lives. With the increase of young people using a camera phone to portray themselves within social networking sites, these methods may be more feasible for young people. We recognise that upon reflection the camera can potentially alter young people's private spaces to public spaces, but young people are increasingly presenting these spaces and concomitant hidden behaviour in virtual and mediated spaces (Lincoln 2002). It could be in these such areas of future research that key insights can be provided to explore the central research aim of this project looking at how mega events may be linked, or not, to changes and shifts in attitudes towards sports participation and physical activity. Researchers may potentially gain access to back spaces, delineated by the young people that are not often disclosed and are less accessible to the researcher (Bates 2015) and elder family members. They can also potentially change existing hierarchical relationships (Plowman \& Stephenson 2012).

\section{Conclusion and reflections on the specific methodological use of video diaries}

This paper has a dual focus to examine the use of video diaries and their value as supplementary methods in qualitative research examining the influence of the London 2012 Olympics and to explore the influence of these games on family attitudes, opinions and perceptions towards their sports participation and physical activity. We found that some family members revealed that they were enthused by the representation of successful athletes. The interviews provided insight into their perceptions of the athletes and the impact on the families' everyday lives,and 
we found thatvideos were a useful addition to this method because they provided access to their raw thoughts at the time of the mega- event. Our data also revealed that young people consumed aspects of the games, but few were inspired or motivated to participate in response to their viewing. Furthermore, we saw a decrease in interaction amongst the family and a decrease in participation due to family consumption of the games. Some younger members of the family were more isolated from the family unit because they were apathetic about watching the games. What is particularly, pertinent is that the freedom of the diary method also gave additional, valued and perhaps more subtle nuanced insights into deconstructing leveraging legacy and the supposed virtuous cycle of mega events generating participation gains (Veal 2003, Coalter, 2007).

Video diaries are an invaluable tool for accessing the families' responses to mega-events during the period in which they are hosted. However, some diarists, notably younger family members, rejected this method and the potential it has to shame and/or embarrass them in the public spaces of their lives. In the back space of their home, away from the potential embarrassment of their peers, they performed their sports participation activities, and used the video diaries to express the emotional pressures of conforming to cultural expectations of their identity: that does not participate in the sports and PA publicly.

It should also be recognised that use of the video diaries perhaps contributed towards one family leaving the project midway through due to the time requirements of the research. This kind of in-depth, time consuming project is also limited by the difficulty the project team faced in initial recruitment to sign up five families. Extensive regional marketing through online and radio presence was also needed to gain access to committed families. This is a distinct challenge of such intensive qualitative research. However, measures can be taken to encourage participation and continual commitment. Feedback from our participants suggested that initial training in the camera, discussion of expectations by researchers, prompt sheets and contact from the researchers ensured sustained usage and understanding of the project data capture approach. Whilst the contact developed by the researchers can be perceived to 'militate against the empowering claim of video diaries', (Jones 2014, p.11) we argue that it should not be disregarded. The processes of diary making by the participants inform 'our ethnographic knowledge' (Pink 2013, p. 98).

The implications of this research are that video diaries can be used in combination with other qualitative methods for analysis of the forthcoming Rio 2016 Olympic Games and the sports participation legacy. We have shown that whilst these methods are invaluable for accessing responses and changes in behaviour for some respondents, alternative forms of this method can be used when examining young people. Smart phone technology can potentially engage young people, and develop understanding of the spaces in which peer relationships exists virtually in blogging and social networking sites. Furthermore, we would like to draw attention to the further uses of video diaries to examine future sports participation and supplementary analysis of the long-term legacy. Video is sharable, participants can be invited to reflect and discuss it. Researchers therefore can ask respondents to return to their diaries and comment on any changes in their level of motivation, inspiration and subsequent sports participation. 
We recognise the risk and exploratory nature of this kind of research, notably the limits to accessing complete answers. However, the importance of this work is that it is complementing comprehensive quantitative research, for example in the case of the England Active People Survey data, that doesn't provide insights at local level due to sampling constraints. We hope the tentativeness and incompleteness of these findings will stimulate further research in this case.

\section{References}

Alaszewski, A. 2006. Diaries as a source of suffering narratives: a critical commentary, Health, Risk and Society, 8 (1), 43-58

Bates, C. 2015. Intimate Encounters: making video diaries about everyday life, In: C. Bates, eds. Video Methods Social Science Research in Motion, Oxon: Routledge. 
Bijoux, D., and Myers, J., 2006. Interviews, Solicited Diaries and Photography: 'New' Ways of Accessing Everyday Experiences of Place, Journal of Asia-Pacific Studies, 4 (1), 44-64.

Billings, A, C., and Hardin, M, C., 2013. Megasport in a Mega-City to a Mega-Audience: The Impact of 2012 London Olympic Media, Mass Communication and Society, 16 (6), 847-849.

Billings, A, C., Brown, N, A., Brown, K, A., Leeman, G, M, A., Ličen, S., Novak, D, R., and Rowe, D. 2013. From Pride to Smugness and the Nationalism between: Olympic Media Consumption Effects on Nationalism across the Globe, Mass Communication and Society, (16) 6, 10-932.

Braun, V., and Clarke, V., 2013. Successful Qualitative Research: A Practical Guide for Beginners, London: Sage.

Carmichael, F., Grix, J., and Marqués, D, P., 2013. The Olympic legacy and participation in sport: an interim assessment of Sport England's Active People Survey for sports studies research, International Journal of Sport Policy and Politics, 5 (2), 229-244.

Carter, R, V., and Lorenc, T., 2013. A qualitative study into the development of a physical activity legacy from the London 2012 Olympic Games. Health Promotion International. September 19, 2013. Available from:

http://heapro.oxfordjournals.org/content/early/2013/09/18/heapro.dat066.abstract, [Accessed 07/04/2014].

Cherrington, J., and Watson, B. 2010. Shooting a diary, not just a hoop: using video diaries to explore the embodied everyday contexts of a university basketball team. Qualitative Research in Sport and Exercise, 2 (2), 267-281.

Coalter, F., 2004. Stuck in the blocks? A sustainable sporting legacy, In: A. Vigor, M. Mean, and C. Tims, eds. After the Gold Rush: A sustainable Olympics for London, Demos/IPPR, London, 91-108.

Darko, N., 2012. Rugby Union Men: Body Concerns. Thesis (PhD). Loughborough University Department of Culture Media and Sport (DCMS), 2009. London 2012 Olympic and Paralympic Games Impacts and Legacy Evaluation Framework. London: DCMS.

Frawley, S., 2013. Sport Participation legacy and the hosting of mega-sport events, In: G. Richards, M. de Brito, L. Wilks, eds. Exploring the Social Impacts of Events. London: Routledge, 97-110.

Gibson, B. E., 2005. Co-producing video diaries: The presence of the "absent" researcher. International Journal of Qualitative Methods, 4 (3), Article 3.

Available from:

http://www.ualberta.ca/ iiqm/backissues/4_4/pdf/gibson.pdf, [Accessed 10/04/2014]. 
Gibson, O., 2013. London 2012 Olympic Games legacy questioned as young people shun sport, The Guardian, Thurs 12th Dec 2013.

Available from:

http://www.theguardian.com/sport/2013/dec/12/london-2012-olympic-legacy-young-peopleshun-sport, [Accessed, 06/04/2014].

Goffman, E., 1959. The Presentation of the Self in Everyday Life. London: Allen Lane.

Green, K., 2012. London 2012 and sports participation: The myths of legacy, June 2012 Significance, The Royal Statistical Society.

Hawkes, G., Houghton, J., and Rowe, G., (2009) Risk and worry in everyday life: Comparing diaries and interviews as tools in risk perception research, Health, Risk \& Society, 11 (3), 209230.

Holliday, R., 2004. "Reflecting the Self”, In: P. Sweetman, and C. Knowles, eds. Picturing the Social Landscape: Visual Methods and the Sociological Imagination, London: Routledge, 4649.

Horne, J., and Whannel, G., 2012. Understanding the Olympics, Oxon: Routledge.

Jewitt, C., 2012. An introduction to using video, National Centre for Research Methods Working Paper 03/12, National Centre for Research Methods, London: Institute of Education.

Jones, R.L., Fonseca, J., De Martin Silva, L., Davies, G., Morgan, K., and Mesquita, I. (2014) The promise and problems of video diaries: building on current research, Qualitative Research in Sport, Exercise and Health. Available from:

http://dx.doi.org/10.1080/2159676X.2014.938687, accessed [25/09/2014].

Kennelly, J., and Watts, P., 2012. Seeing Olympic effects through the eyes of marginally housed youth: changing places and the gentrification of East London, Visual Studies, Olympics Special Issue, 27 (2), 151-160.

Lincoln, S. 2012. Youth Culture and Private Space, Palgrave New York.

Lines, G., 2001. Villains, fools or heroes? Sports stars as role models for young people, Leisure Studies, 20 (4), 285-303.

Mackintosh, C., Darko, N., Rutherford, Z., and Wilkins, H, 2014. (2014) A qualitative study of the impact of the London 2012 Olympics on families in the East Midlands of England: lessons for sports development policy and practice, Sport, Education and Society,

Available from:

http://dx.doi.org/10.1080/13573322.2014.881337, [Accessed 28/09/2014)

Mason, J., 2002. Qualitative Researching, London: Sage. 
Morley, D. 1986. Family Television, Cultural Power and Domestic Leisure, London: Routledge

Murray, L., 2009. Looking at and looking back: visualization in mobile research, Qualitative Research, 9, 469-488.

Murthy, D., 2008. Digital Ethnography: An Examination of the Use of New Technologies for Social Research, Sociology, 42 (5), 837-855.

Pink, S., 2013. Doing Visual Ethnography, London: Sage.

Plowman, L., and Stevenson, O., 2012. Using mobile phone diaries to explore children's everyday lives, Childhood, 19 (4), 539-553.

Phoenix, C., and Smith, B., 2011. eds. The World of Physical Culture in Sport and Exercise, Visual Methods for Qualitative Research, London: Routledge

Rose, G., 2007. Visual Methodologies: An Introduction to Interpreting Visual Materials, (2nd ed.) London: Sage

Smith, B., and Sparkes, A., 2013. Qualitative Research Methods in Sport, Exercise and Health: From Process to Product, Oxon: Routledge.

Smith, B., and Caddick, N. (2012) Qualitative methods in sport: a concise overview for guiding social scientific sport research, Asia Pacific Journal of Sport and Social Science, 1 (1), 60-73.

Sport England, 2012. Places People Play - delivering a mass participation sporting legacy from the 2012 Olympic and Paralympic Games,

Available from:

http://archive.sportengland.org/about_us/places_people_play.aspx, [Accessed 06/04/2014].

Sport England, Active People Survey, 7 Q2- 8 Q2 2013- 2014. Sport participation factsheet: summary of results for England, April 2012 - April 2013, London: Sport England

Steen, R. 2012. The view from the pressbox-rose tinted spectacle? In: J, P., Sugden, A., Tomlinson, eds. 2012. Watching the Olympics: Politics, Power and Representation, Oxon: Routledge, 213-227.

Tang, T., and Cooper, R., 2013. Olympics Everywhere: Predictors of Multiplatform Media Uses During the 2012 London Olympics, Mass Communication and Society, 16 (6), 850-868.

The Telegraph, 2011. London 2012 Olympics: Lord Coe rejects criticism of 'legacy' planning, The Telegraph, 24 ${ }^{\text {th }}$ May 2011.

Available from:

http://www.telegraph.co.uk/sport/olympics/8534433/London-2012-Olympics-Lord-Coerejects-criticism-of-legacy-planning.html, [Accessed: 28/04/2014].

Saldaña, J., 2013. The Coding Manual for Qualitative Researchers, London: Sage. 
Silk, M., 2011. Towards a Sociological Analysis of London 2012, Sociology, 45 (5), 733 -748.

Veal, A. J., Toohey, K., and Frawley, S. 2012. The sport participation legacy of the Sydney 2000 Olympic Games and other international sporting events hosted in Australia, Journal of Policy Research in Tourism, Leisure and Events, 4 (2), 155-184.

Weed, M., Coren, E., and Fiore, J., 2009. A systematic review of the evidence base for developing a physical activity and health legacy from the London 2012 Olympic and Paralympic Games, Canterbury: Canterbury: Centre for Sport, Physical Education \& Activity Research (SPEAR). Canterbury Christ Church University.

Veal, A, J., 2003. Tracking change: leisure participation and policy in Australia, 1985-2002. Annals of Leisure Research, 6 (3), 245-277.

Würfel, G., 2012. Go for Gold, Visual Studies, Olympics Special Issue, 27 (2), 141-147. 
